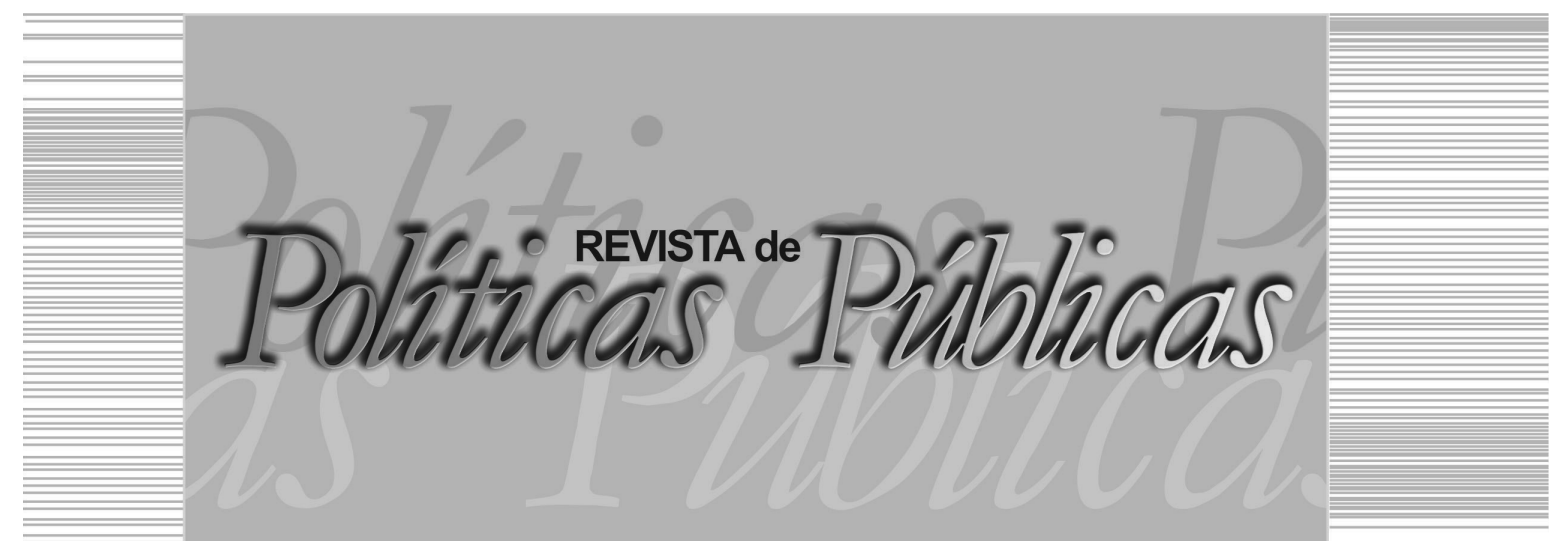

\title{
QUESTÕES CONTEMPORÂNEAS NA GESTÃO PÚBLICA DE RESÍDUOS SÓLIDOS: análise dos principios da Política Nacional de Resíduos Sólidos a partir de seus objetivos e instrumentos
}

\author{
Ana Cristina Bagatini Marotti ${ }^{1}$ \\ Universidade Federal de São Carlos (UFSCar) \\ Gisele Sant'Ana Fiorini Pereira ${ }^{2}$ \\ Universidade de São Paulo (USP) \\ Erica Pugliesi $i^{3}$ \\ Universidade Federal de São Carlos (UFSCar)
}

\section{Resumo}

O governo federal instituiu, em 2010, a Política Nacional dos Resíduos Sólidos (PNRS), a qual estabelece princípios, objetivos e instrumentos que regulamentam a gestão e o gerenciamento de resíduos sólidos. Este estudo apresenta uma análise do atendimento dos princípios desta lei pelos seus objetivos e instrumentos. Para isso, elabora matrizes de correlação, buscando analisar a existência de relações entre os princípios e objetivos, e os princípios e instrumentos.

\footnotetext{
Bacharel em Gestão e Análise Ambiental, Mestranda do Programa de Pós-graduação em Ciências Ambientais pela Universidade Federal de São Carlos (UFSCar). E-mail: ana marotti@hotmail.com / Universidade Federal de São Carlos - UFSCar: Rod. Washington Luís, km 235, SP-310, São Carlos - SP. CEP 13565-905

2 Bacharel e Licenciada em Ciências Biológicas, Mestranda do Programa de Pós-graduação em Ciências Ambientais pela Universidade Federal de São Carlos (UFSCar), Técnica de Assuntos Administrativos da Universidade de São Paulo (USP). E-mail: gisele@cirp. usp.br / Universidade de São Paulo - USP: Prédio Administração Central - Rua Praça do Relógio, 109, Butantã, São Paulo - SP. CEP 05508-050

3 Bacharel em Farmácia Bioquímica, Doutor em Ciências da Engenharia Ambiental pela USP, Professor Adjunto do Departamento de Ciências Ambientais da UFSCar. E-mail: epugliesi@ufscar.br
} 
Verifica que as relações estabelecidas não obedecem a uma correspondência total entre os elementos, havendo a complementação entre objetivos e instrumentos. Conclui que a quantidade de relações estabelecidas não garantem a aplicação plena do princípio, denotando a complexidade do conteúdo da política e a importância de melhor compreendê-la para a efetivação da política pública. Palavras-chave: Política Nacional de Resíduos Sólidos, Gestão de Resíduos, Princípios, Correlação.

\title{
CONTEMPORARY ISSUES IN THE PUBLIC
}

MANAGEMENT OF SOLID WASTE: analysis of the principles of National Waste Policy based on its objectives and instruments

\begin{abstract}
The federal government instituted, in 2010 the National Waste Policy (NWS), which establishes principles, objectives and instruments that regulate the management of solid waste. This study presents an analysis of compliance with the principles of this law through its objectives and instruments. For this, correlation matrices were elaborated, seeking to analyze the existence of relations between principles and objectives, and principles and instruments. It is verified the relations established do not correspond to a total correspondence between the elements, existing a complementation between objectives and instruments. However, the number of relationships established does not guarantee full application of the principal, denoting the complexity of the content of the policy and the importance of better understanding it for the effectiveness of public policy. Key words: National Waste Policy, waste management, principles, correlation.
\end{abstract}

\section{INTRODUÇÃO}

O crescimento populacional, o desenvolvimento econômico e o avanço da tecnologia vêm causando mudanças nos padrões de produção e de consumo da sociedade e, consequentemente, a exploração dos recursos naturais e o aumento da geração dos resíduos sólidos. Esse modelo de desenvolvimento tem se mostrado insustentável, resultando em sérios impactos negativos ao meio ambiente e à sociedade.

Os resíduos sólidos urbanos (RSU) descartados de forma inadequada causam a degradação do meio ambiente e diversos problemas à saúde da população. A geração de resíduos sólidos tem aumentado, segundo Gouveia (2012), tanto em quantidade quanto em diversidade e periculosidade - principalmente nos grandes centros urbanos. Além dos crescentes aumentos de volume, as novas tec- 
nologias agregaram materiais sintéticos e perigosos na composição desses resíduos, causando degradação do ar, solo, água e da saúde humana.

Para a manutenção da qualidade ambiental e de vida da população é fundamental o manejo adequado dos resíduos sólidos produzidos pelas diversas atividades humanas. Gouveia (2012) considera que o grande desafio para a gestão de resíduos sólidos é formular políticas públicas, integrando aspectos econômicos, sociais e ambientais, visando à proteção do meio ambiente e da saúde humana, garantindo também a inclusão social da população que trabalha diretamente com estes resíduos.

A atenção à formulação de políticas públicas é extremamente necessária, e seus desafios compreendem não só a área ambiental, como todas as demais. Sendo utilizadas como ferramenta das decisões do governo, as quais transformam os propósitos de plano de governança em programas e reais ações, evidenciam seu caráter como instrumento fundamental de gestão, interferindo diretamente na sociedade em forma de direitos e deveres aos cidadãos e aos governos. (SOUZA, 2006).

No sentido da busca da promoção de um ambiente saudável e equilibrado aos cidadãos, minimizar os impactos antrópicos em sociedade, e diminuir a fragilidade em que se encontrava a gestão de resíduos sólidos como política pública, o governo federal brasileiro aprovou em agosto de 2010 a Política Nacional dos Resíduos Sólidos (PNRS - Lei ${ }^{\circ} 12.305$, de 2 de agosto de 2010), que estabelece a prevenção e a redução dos resíduos como prioridade, estimulando a adoção de padrões sustentáveis de produção e de consumo, adota instrumentos de incentivo à reutilização e reciclagem dos resíduos e regula a disposição final ambientalmente adequada dos rejeitos. (BRASIL, 2010).

\section{A POLÍTICA NACIONAL DE RESÍDUOS SÓLIDOS}

A PNRS foi instituída pela Lei $n^{0} 12.305 / 2010$ e estabelece princípios, objetivos e instrumentos que fomentam, regulamentam e instituem aspectos de gestão e gerenciamento de resíduos sólidos no país. Todos os setores sociais estão sujeitos à observância desta lei, sendo direta ou indiretamente responsáveis pela geração de resíduos e por sua gestão e gerenciamento, incentivando ações integradas e compartilhadas entres os mesmos. (BRASIL, 2010). No campo 
competencial, a PNRS se adéqua aos objetivos do federalismo cooperativo vigente, ao se apresentar como uma norma geral federal que estabelece diretrizes universais para os estados, distrito federal e municípios, sem, contudo, tirar-lhes autonomia para suplementarem as diretrizes gerais, adaptando-as adequadamente às diversidades regionais e interesses locais. (YOSHIDA, 2012).

\subsection{Histórico e surgimento da Lei $\mathrm{n}^{0} \mathbf{1 2 . 3 0 5 / 2 0 1 0}$}

Apesar de a PNRS ser datada de 2010, vinte e um anos de tramitação e discussões precederam sua promulgação, sendo considerada tardia quando comparada às demais políticas ambientais. Seu processo de tramitação foi iniciado no ano de 1989, e, dois anos depois, o projeto de lei chega à Câmara dos Deputados, denominado Projeto de Lei $\mathrm{n}^{\circ} 203$, de 1 de abril de 1991. Após mais dezenove anos de discussões e tramitação jurídica, teve sua aprovação no ano de 2010, regulamentada pelos Decretos $\mathrm{n}^{\mathrm{o}} 7.404$ e $\mathrm{n}^{\mathrm{o}} 7.405$, de 23 de dezembro de 2010. (JURAS, 2012; NASCIMENTO NETO; MOREIRA, 2010).

Anteriormente à publicação da PNRS, diversos dispositivos e normativas legais já traziam a temática de resíduos sólidos em seus conteúdos. Algumas, de forma mais geral e indireta, tratando o meio ambiente em sua forma ampla, como o artigo $225^{\circ}$ da Constituição Federal (CF) de 1988, "Todos têm direito ao meio ambiente ecologicamente equilibrado, bem de uso comum do povo e essencial à sadia qualidade de vida, impondo-se ao Poder Público e à coletividade o dever de defendê-lo e preservá-lo para as presentes e futuras gerações.” (BRASIL, 1988).

Da mesma forma, a Política Nacional do Meio Ambiente (PNMA), Lei $\mathrm{n}^{\circ} 6.938$ de 31 de agosto de 1981, apresenta questões fundamentais e inovadoras na área ambiental, além de reforçar a descentralização nas políticas públicas, incumbindo maiores responsabilidades para os entes federativos de unidades territoriais menores, em última instância, os municípios. (BUARQUE, 1999).

Os dispositivos legais que precederam a PNRS e regulam questões específicas dos resíduos sólidos no país, são representados pelas resoluções do Conselho Nacional do Meio Ambiente (CONAMA), que abordam disposições pontuais (ARAÚJO, 2013; GODOY, 2013) como para resíduos perigosos, resíduos industriais, de construção civil, de serviços de saúde e pilhas e baterias, por exemplo; além 
da Política Federal de Saneamento Básico (PFSB), Lei n ${ }^{\circ} 11.445$, de 5 de janeiro de 2007, que abrange os serviços que compõem o saneamento básico, sendo: abastecimento de água potável, esgotamento sanitário, drenagem e manejo das águas pluviais, e limpeza urbana e manejo de resíduos sólidos. (BRASIL, 2007). A PFSB dispõe a respeito dos resíduos sólidos a partir da abordagem dos serviços públicos de saneamento, sendo insuficiente como dispositivo legal para regulamentar a totalidade e diversidade dos resíduos sólidos.

Portanto, a promulgação da Lei $\mathrm{n}^{\circ} 12.305 / 2010$ veio sanar a lacuna legislativa existente, evidenciando sua importância ao congregar as disposições relativas à gestão e gerenciamento dos resíduos sólidos, disciplinando as atividades técnicas e administrativas, definindo as responsabilidades e corresponsabilidades e contribuindo no avanço das questões legais e no aprimoramento da gestão ambiental como um todo.

\title{
2.2 Os Princípios da Política Nacional de Resíduos Sólidos
}

Gallupo (1999) afirma que os princípios podem ser entendidos como as normas gerais de um sistema. Os princípios podem ser compreendidos, portanto, como orientadores na busca do cumprimento dos objetivos de determinada lei. Por outro lado, os instrumentos são mecanismos utilizados pela administração pública com o intuito de atingir os objetivos da política. Este entendimento é aplicado às políticas públicas ambientais brasileiras a partir da publicação da PNMA e se faz presente na estrutura da PNRS, conforme apresentamos a seguir.

\section{A Lei $n^{0} 12.305 / 2010 \mathrm{em}$ seu art. $4^{\circ}$ estabelece:}

\begin{abstract}
A Política Nacional de Resíduos Sólidos reúne o conjunto de princípios, objetivos, instrumentos, diretrizes, metas e ações adotados pelo Governo Federal, isoladamente ou em regime de cooperação com Estados, Distrito Federal, Municípios ou particulares, com vistas à gestão integrada e ao gerenciamento ambientalmente adequado dos resíduos sólidos. (BRASIL, 2010).
\end{abstract}

Tais princípios, objetivos e instrumentos que atualmente contemplam a PNRS foram alterados e incluídos ao longo dos mais de vinte anos de tramitação - como já citado; dessa forma, tal conjunto que nos é apresentado, sofreu transformações ao longo dos anos até se formar na estrutura atual, contemplando, onze princípios, quinze objetivos e dezoito instrumentos. 
Os princípios são apresentados no Capítulo II, artigo $6^{\circ}$ do inciso I ao inciso XI da PNRS, sendo que os primeiros a serem elencados são os princípios da prevenção e da precaução. Ambos são complementares, porém, se distinguem a partir do preceito de que o princípio da prevenção se dá na ação prévia, a fim de evitar, em primeira instância, os impactos negativos que são já concretos quanto a sua ocorrência - se evitar não for possível, cabe, posteriormente, minimizar ou mitigá-lo. Já o princípio da precaução aplica-se quando não se tem a certeza ou comprovação dos danos, porém, mesmo com a incerteza, medidas de precaução são tomadas. As exatas distinções entre a prevenção e precaução ainda são nebulosas, não existindo consenso entre os estudiosos, porém, Machado (2012) defende que o incerto não é algo necessariamente inexistente, portanto justifica-se o fato de que seja avaliado ou pesquisado.

Os princípios que prosseguem são o poluidor-pagador e o protetor-recebedor. A PNMA em seu artigo $4^{\circ}$, inciso VII, visa a "[...] imposição, ao poluidor e ao predador, da obrigação de recuperar e/ ou indenizar os danos causados e, ao usuário, da contribuição pela utilização de recursos ambientais com fins econômicos." (BRASIL, 1981). Dessa forma, em concordância com a PNMA, o princípio do poluidor-pagador é incluído na PNRS, de forma que, o agente que poluiu deve pagar pela poluição causada, restaurando o dano ambiental provocado. (RAUBER, 2011). De forma complementar tem-se o princípio do protetor-recebedor, que, partindo de incentivos - diferentemente do descrito anterior que parte de punições - visa compensar o agente que protege ou salvaguarda um bem ambiental, beneficiando o meio ambiente e a coletividade. (RAUBER, 2011). Tal princípio é de recente criação doutrinária, sendo que sua primeira instituição a nível federal aparece exatamente na PNRS. (MACHADO, 2012).

No inciso III da PNRS, estabelece-se o princípio da visão sistêmica, o qual indica que a gestão dos resíduos sólidos deve considerar as variáveis ambiental, social, cultural, econômica, tecnológica e de saúde pública. (BRASIL, 2010). A visão sistêmica deve conduzir a análise sobre um conjunto de diversos fatores, e não de forma isolada, a fim de praticar a interdisciplinaridade e transversalidade. (MACHADO, 2012).

A seguir apresenta-se o princípio do desenvolvimento sustentável. O conceito de desenvolvimento sustentável há muito é dis- 
cutido, envolvendo diferentes abordagens. Uma das definições mais difundidas é estabelecida em 1987 pela Comissão Brundtland, no relatório Nosso Futuro Comum, que apresenta o desenvolvimento sustentável para o discurso público, como o desenvolvimento que visa suprir as necessidades atuais sem comprometer as das gerações futuras. (ORGANIZAÇÃO DAS NAÇÕES UNIDAS, 2016). O termo está presente em outros incisos da PNRS, como, por exemplo, em um de seus objetivos, definidos no artigo $7^{\circ}$, " [...] estímulo à rotulagem ambiental e ao consumo sustentável.", e em seu art. $3^{\circ}$, onde define gestão integrada de resíduos sólidos como "[...] conjunto de ações voltadas para a busca de soluções para os resíduos sólidos, de forma a considerar as dimensões política, econômica, ambiental, cultural e social, com controle social e sob a premissa do desenvolvimento sustentável." (BRASIL, 2010).

O quinto princípio presente é o princípio da ecoeficiência, entendido como a compatibilização entre a oferta de bens e serviços qualificados com preços competitivos, que satisfaçam as necessidades humanas e que tragam qualidade de vida e a redução do impacto ambiental e do consumo de recursos naturais a um nível mínimo, considerando a capacidade de sustentação estimada do planeta. (BRASIL, 2010). Ressalta-se também a forte relação entre este princípio com o princípio do desenvolvimento sustentável (MACHADO, 2012), sendo a ecoeficiência um fator de importância e que contribui para a aplicação deste conceito.

O sexto princípio apresentado é o da cooperação, a qual deve ocorrer entre as diferentes esferas do poder público, o setor empresarial e demais segmentos da sociedade. Machado (2012) faz uma ressalva, ao considerar que o termo cooperação pode aparentar indeterminado e passar uma mensagem somente utópica, porém, esse pretexto é completamente distante do que a lei pretende com tal princípio, indicando que o comprometimento deve ser multissetorial. Verdan (2013) complementa este raciocínio ao salientar que o princípio da cooperação representa o ideal de uma conjunção de esforços por meio de ações conjuntas e não pulverizadas.

Para abordar a temática do princípio da responsabilidade compartilhada, preceito inovador nas políticas públicas ambientais brasileiras, faz-se necessário compreender minimamente o conceito de ciclo de vida dos produtos. Tal conceito é trazido pela própria Lei 12.305/2010, em seu artigo $3^{\circ}$, inciso IV, como uma "[...] série 
de etapas que envolvem o desenvolvimento do produto, a obtenção de matérias-primas e insumos, o processo produtivo, o consumo e a disposição final." (BRASIL, 2010). Partindo de tal conceito, define, também em seu artigo $3^{\circ}$, a responsabilidade compartilhada pelo ciclo de vida dos produtos, como um conjunto de ações de agentes envolvidos no ciclo de vida do produto, "[...] fabricantes, importadores, distribuidores e comerciantes, dos consumidores e dos titulares dos serviços públicos de limpeza urbana e de manejo dos resíduos sólidos.", que visem minimizar os impactos negativos da geração de resíduos, a partir da gestão adequada e de acordo com as premissas da própria PNRS. (BRASIL, 2010). A responsabilidade compartilhada é considerada um dos temas centrais da lei, e um dos grandes desafios a serem alcançados devido à necessidade do envolvimento de diversos agentes e setores da sociedade. (FARIA, 2012; MACHADO, 2012).

O princípio do reconhecimento do resíduo sólido reutilizável e reciclável como um bem econômico e de valor social, gerador de trabalho e renda e promotor de cidadania, perpassa pela ordem de prioridades de gestão de resíduos sólidos trazidas no artigo $9^{\circ}$, em que se define que na gestão e gerenciamento de resíduos sólidos, a ordem de prioridade deve ser "[...] não geração, redução, reutilização, reciclagem, tratamento dos resíduos sólidos e disposição final ambientalmente adequada dos rejeitos." (BRASIL, 2010). Portanto, a reutilização e reciclagem são opções viáveis e incentivadas, dentro da ordem de prioridade estabelecida, que também auxiliam na não geração e redução dos resíduos. Ressalta-se que o princípio compreende o resíduo sólido, não apenas como bem econômico, mas incumbe a ele valores sociais, gerador de trabalho, renda e cidadania - o que evidencia a integração dos catadores de materiais recicláveis e o incentivo às cooperativas, vinculadas à eliminação dos lixões - proporcionando a inclusão social e emancipação econômica dos catadores. (MACHADO, 2012).

Outro princípio apresentado por esta lei é o princípio do respeito às diversidades locais e regionais. Segundo a CF de 1988, em seu art. 23, caput e inciso VI, a proteção do meio ambiente e o combate à poluição é de competência comum da União, dos Estados, do Distrito Federal e dos Municípios. Machado (2012) destaca que a diversidade biológica, socioeconômica e geográfica regional e local não pode justificar o descumprimento da norma geral, devendo-se fazer adaptações do geral para o particular. Assim, os municípios 
passam a desempenhar um papel de extrema importância na gestão dos resíduos sólidos. Por outro lado, a aplicação deste princípio garante a multiplicidade dos modelos de gestão a serem adotados pelos distintos entes federativos, considerando-se a diversidade cultural, social e econômica apresentada no país.

O princípio do direito da sociedade à informação, segundo Machado (2012), traz a obrigação da divulgação das informações, tornando-as disponíveis a todos. Além disso, a PNRS é destacada por caracterizar a desinformação e a informação incompleta e atrasada como crime. Dessa forma, a PNRS apresenta a importância da transparência, organização, rapidez nas respostas, coleta e fornecimento contínuo de dados e facilidade de acesso das informações.

O princípio apresentado no inciso $\mathrm{X}$ é o princípio do direito da sociedade ao controle social. Na PNRS o controle social é definido como mecanismos que assegurem o direito da sociedade em participar de processos de elaboração, implantação e avaliação de políticas públicas relacionadas com o tema de resíduos sólidos. Portanto, este princípio visa possibilitar o direito da participação social e não de enfraquecer o poder dos órgãos públicos na gestão e gerenciamento dos resíduos sólidos.

Por fim, no inciso XI, são apresentados os princípios da razoabilidade e da proporcionalidade que, segundo Pires (2007), são apresentados nas legislações para que estas sejam pautadas na boa razão e na justa medida, impedindo abusos do Estado. Estes princípios se distinguem pelo fato de o princípio da proporcionalidade se apresentar como um meio para o legislador decidir com critérios de bom senso e a ponderação. Já o princípio da razoabilidade é a utilização da igualdade e da razão, sendo uma maneira de se atingir a proporcionalidade. (PIRES, 2007).

Machado (2012) alerta para a importância dos princípios estabelecidos na PNRS como norteadores da implantação da mesma, e a necessidade de que estes sejam interpretados de forma sistêmica com todo o conteúdo da Lei, ou seja, considerando também suas definições (art. $3^{\circ}$ ), os objetivos (art. $7^{\circ}$ ), as disposições gerais (art. $4^{\circ}$ ), os instrumentos $\left(\operatorname{art.~} 8^{\circ}\right.$ ), bem como as disposições preliminares contidas no capítulo I do título III. Por outro lado, para a efetivação enquanto política pública, os princípios da PNRS precisam estar relacionados aos objetivos e instrumentos propostos. 
A partir das considerações a respeito da PNRS e os aspectos abordados em seus princípios, faz-se necessário compreender a relação entre os princípios, objetivos e instrumentos propostos para a gestão dos resíduos sólidos na medida em que se tornam essenciais para a efetivação da política pública.

\section{ASPECTOS METODOLÓGICOS}

A PNRS é a temática central de discussão no presente artigo, em função de sua importância para a gestão e o gerenciamento de resíduos sólidos no país. Sua estrutura estabelecida em princípios, objetivos e instrumentos permite o estudo destes elementos, correlacionando-os, em vista de melhor compreender as disposições da própria lei.

Dessa forma, para a análise e compreensão das relações existentes entre os princípios e os objetivos e instrumentos, foram elaboradas duas matrizes de correlação (Quadros 1 e 2), a primeira referente à correlação existente entre os princípios e objetivos e a segunda entre os princípios e instrumentos. As matrizes permitem dois tipos de análise: a correlação entre princípios e os objetivos e instrumentos; e a identificação qualitativa das correlações existentes.

Para a elaboração das matrizes de correlação, os onze princípios foram identificados com as letras de $\mathrm{A}$ a $\mathrm{N}$, sendo que alguns foram desmembrados ao se identificar a necessidade de análise separadamente. A identificação das relações entre os objetivos e instrumentos com os princípios é apresentada na coluna Correlação de cada matriz.

Para a avaliação qualitativa do atendimento dos princípios, utilizou-se uma escala de 1 a 4, indicada nas colunas Atendimento pelos Objetivos e Atendimento pelos Instrumentos, na qual 1 indica que nenhum objetivo ou instrumento se relaciona com aquele princípio; 2, o princípio é pouco relacionado aos objetivos ou aos instrumentos; 3, o princípio é parcialmente relacionado aos objetivos ou instrumentos; e, 4, o princípio possui grande relação aos objetivos ou instrumentos, sendo esta a maior escala atribuída. Dessa forma, é possível identificar - além da relação com os objetivos e instrumentos - de que forma essa relação ocorre, contemplando mais ou menos a aplicação do princípio analisado. 
QUESTÕES CONTEMPORÂNEAS NA GESTÃO PÚBLICA DE RESÍDUOS SÓLIDOS: análise dos princípios da Política Nacional de Resíduos Sólidos a partir de seus objetivos e instrumentos

De forma complementar e para melhor visualização e compreensão da rede de correlações identificadas, os resultados são apresentados em diagramas. No diagrama, os princípios são apresentados em uma escala de cinza, que representa o atendimento dos mesmos, e as setas representam as relações existentes com o objetivo ou instrumento. No diagrama não foram incluídos os instrumentos que não apresentaram correlação, devido à inexistência de correlação a ser representada.

\section{CORRELAÇÃO ENTRE PRINCÍPIOS E OBJETIVOS DA PNRS}

Partindo da premissa que a implementação da PNRS é intrinsecamente dependente da relação entre os princípios propostos, os objetivos e instrumentos, são apresentadas no Quadro 1 as relações existentes entre os princípios e objetivos da PNRS, e o atendimento dos princípios a partir dos objetivos correlacionados.

Quadro 1 - Matriz de correlação entre princípios e objetivos da Política Nacional de Resíduos Sólidos

\begin{tabular}{|c|c|c|c|c|}
\hline \multicolumn{3}{|c|}{ PRINCIIPIOS } & \multicolumn{2}{|l|}{ OBJETIVOS } \\
\hline Item & Descrição & $\begin{array}{l}\text { Atendimento } \\
\text { pelos } \\
\text { Objetivos }\end{array}$ & Descrição & $\begin{array}{l}\text { Correlação com } \\
\text { os Princípios }\end{array}$ \\
\hline A & $\begin{array}{l}\text { I - a prevençãa e a } \\
\text { precaução }\end{array}$ & 4 & $\begin{array}{l}\text { I - proteção da saúde pública e da } \\
\text { qualidade ambiental }\end{array}$ & $A ; E$ \\
\hline B & $\begin{array}{l}\text { Ila - o poluidor- } \\
\text { pagador }\end{array}$ & 1 & $\begin{array}{l}\text { ॥ - não geração, redução, } \\
\text { reutilização, reciclagem e tratamento } \\
\text { dos resíduos sólidos, bem como } \\
\text { disposição final ambientalmente } \\
\text { adequada dos rejeitos }\end{array}$ & $A ; E ; F ; H$ \\
\hline C & $\begin{array}{l}\text { Ilb - o protetor- } \\
\text { recebedor }\end{array}$ & 2 & $\begin{array}{l}\text { III - estímulo à adoção de padrões } \\
\text { sustentáveis de produção e consumo } \\
\text { de bens e serviços }\end{array}$ & $E ; F$ \\
\hline D & $\begin{array}{l}\text { III - a visão } \\
\text { sistêmica, na gestão } \\
\text { dos resíduos sólidos, } \\
\text { que considere as } \\
\text { variáveis ambiental, } \\
\text { social, cultural, } \\
\text { econômica, } \\
\text { tecnológica ede } \\
\text { saúde pública }\end{array}$ & 3 & $\begin{array}{l}\text { IV - adoção, desenvolvimento e } \\
\text { aprimoramento de tecnologias } \\
\text { limpas como forma de minimizar } \\
\text { impactos ambientais }\end{array}$ & $A ; E ; F$ \\
\hline
\end{tabular}


Ana Cristina Bagatini Marotti | Gisele Sant'Ana Fiorini Pereira | Erica Pugliesi

\begin{tabular}{|c|c|c|c|c|}
\hline$E$ & $\begin{array}{c}\text { IV - o } \\
\text { desenvolvimento } \\
\text { sustentável }\end{array}$ & 3 & $\begin{array}{l}\mathrm{V} \text { - redução do volume e da } \\
\text { periculosidade dos resíduos } \\
\text { perigosos }\end{array}$ & $A ; E ; F$ \\
\hline \multirow[b]{3}{*}{$F$} & $\begin{array}{l}\text { V - a ecoeficiência, } \\
\text { mediante a } \\
\text { compatibilização } \\
\text { entre o fornecimento, } \\
\text { a preços }\end{array}$ & \multirow[b]{3}{*}{3} & $\begin{array}{l}\mathrm{VI} \text { - incentivo à indústria da } \\
\text { reciclagem, tendo em vista fomentar } \\
\text { o uso de matérias-primas e insumos } \\
\text { derivados de materiais recicláveis e } \\
\text { reciclados }\end{array}$ & C; E; F;I \\
\hline & competitivos, de & & $\begin{array}{l}\text { VII - gestão integrada de resíduos } \\
\text { sólidos }\end{array}$ & A; D; E; J; L \\
\hline & $\begin{array}{l}\text { necessidades } \\
\text { humanas e tragam } \\
\text { qualidade de vida } \\
\text { e a redução do } \\
\text { impacto ambiental } \\
\text { e do consumo de } \\
\text { recursos naturais } \\
\text { a um nível, no } \\
\text { mínimo, equivalente } \\
\text { à capacidade } \\
\text { de sustentação } \\
\text { estimada do planeta }\end{array}$ & & $\begin{array}{l}\text { VIII - articulação entre as diferentes } \\
\text { esferas do poder público, e destas } \\
\text { com o setor empresarial, com vistas } \\
\text { à cooperação técnica e financeira } \\
\text { para a gestão integrada de resíduos } \\
\text { sólidos }\end{array}$ & $\mathrm{D} ; \mathrm{E} ; \mathrm{G} ; \mathrm{H} ; \mathrm{J}$ \\
\hline G & $\begin{array}{l}\text { VI - a cooperação } \\
\text { entre as diferentes } \\
\text { esferas do poder } \\
\text { público, o setor } \\
\text { empresarial e } \\
\text { demais segmentos } \\
\text { da sociedade }\end{array}$ & 2 & $\begin{array}{l}\text { IX - capacitação técnica continuada } \\
\text { na área de resíduos sólidos }\end{array}$ & I \\
\hline $\mathrm{H}$ & $\begin{array}{l}\text { VII - a } \\
\text { responsabilidade } \\
\text { compartilhada pelo } \\
\text { ciclo de vida dos } \\
\text { produtos }\end{array}$ & 2 & $\begin{array}{l}\text { X - regularidade, continuidade, } \\
\text { funcionalidade e universalização } \\
\text { da prestação dos serviços públicos } \\
\text { de limpeza urbana e de manejo } \\
\text { de resíduos sólidos, com adoção } \\
\text { de mecanismos gerenciais e } \\
\text { econômicos que assegurem a } \\
\text { recuperação dos custos dos serviços } \\
\text { prestados, como forma de garantir } \\
\text { sua sustentabilidade operacional } \\
\text { e financeira, observada a Lei nº } \\
11.445, \text { de } 2010\end{array}$ & $A ; E$ \\
\hline
\end{tabular}


QUESTÕES CONTEMPORÂNEAS NA GESTÃO PÚBLICA DE RESÍDUOS SÓLIDOS: análise dos princípios da Política Nacional de Resíduos Sólidos a partir de seus objetivos e instrumentos

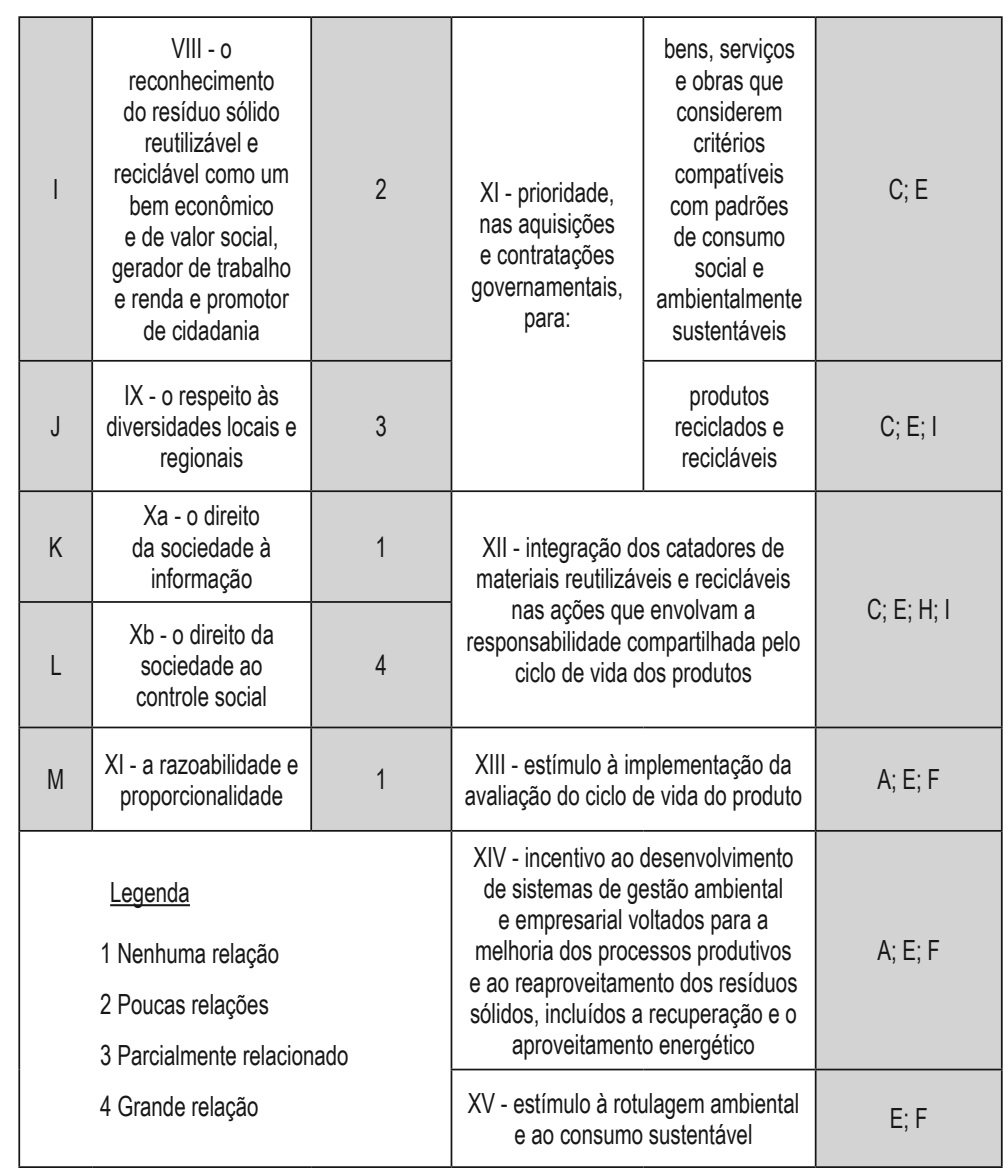

Fonte: Elaborado pelos autores.

Os princípios do poluidor-pagador, o direito da sociedade à informação e os princípios da razoabilidade e da proporcionalidade não apresentam relação direta com objetivos estabelecidos na PNRS, porém, são princípios gerais e aplicáveis às políticas públicas ambientais brasileiras. $\mathrm{O}$ acesso à informação é um direito fundamental previsto no ordenamento jurídico brasileiro a partir da CF de 1988. Os princípios do poluidor-pagador e da razoabilidade e proporcionalidade são princípios gerais de normativas e políticas públicas ambientais, relacionados às penalidades aplicáveis, portanto, sua inclusão na PNRS não tenciona por objetivos e instrumentos 
específicos. Sua importância se dá exatamente ao seu caráter generalista, o qual deve ser considerado para todas as ações e tomadas de decisão que envolvam a lei.

Dentre os princípios que apresentaram poucas relações com os objetivos, temos: o princípio do protetor-recebedor, pois mesmo considerando como objetivo desta lei o incentivo à indústria de reciclagem, dar prioridade nas contratações públicas a produtos reciclados e a serviços que considerem critérios ambientais e integrar catadores de materiais recicláveis na responsabilidade compartilhada dos produtos, o princípio tem um caráter mais amplo, abrangendo diferentes formas de proteção e diversidade de incentivos. O princípio da cooperação também foi considerado pouco relacionado aos objetivos, pois foi identificado um objetivo que contempla a articulação entre as esferas do governo e do setor empresarial, mas não há referência nos objetivos de cooperação dos segmentos da sociedade. Outro princípio pouco relacionado aos objetivos é o da responsabilidade compartilhada pelo ciclo de vida dos produtos, pois pela análise realizada percebeu-se que faltam objetivos que contemplem a definição das responsabilidades nas distintas etapas da cadeia produtiva e reversa. Por fim, o princípio do reconhecimento do resíduo sólido reutilizável e reciclável também foi considerado nesta categoria, já que os objetivos contemplam seu reconhecimento como valor econômico, gerador de trabalho e renda, mas não se relacionam ao reconhecimento destes resíduos como valor social e promotor de cidadania.

Depois de realizadas as análises de correlação, identificou-se que a maioria dos objetivos se relaciona com o atendimento ao princípio do desenvolvimento sustentável (Figuras 1 e 2), porém este foi considerado parcialmente atendido, pois os objetivos instituídos não contemplam os aspectos relevantes à sustentabilidade como os culturais, de governança e participação política. Outro princípio considerado como parcialmente atendido pelos objetivos é o da ecoeficiência, que, embora muitos objetivos se relacionem a este princípio, observaram-se limitações quanto a objetivos que visem o fornecimento de bens e serviços sustentáveis com preços compatíveis e qualificados.

Os princípios da prevenção e da precaução e o princípio do direito da sociedade ao controle social apresentaram as maiores relações com os objetivos propostos. Apesar de apresentarem corre- 
QUESTÕES CONTEMPORÂNEAS NA GESTÃO PÚBLICA DE RESÍDUOS SÓLIDOS: análise dos princípios da Política Nacional de Resíduos Sólidos a partir de seus objetivos e instrumentos

lações distintas com os objetivos da política, o princípio do direito da sociedade ao controle social está diretamente ligado ao direito à informação, que é uma condição essencial para garantir uma efetiva participação da sociedade.

As correlações existentes entre os princípios e objetivos foram variadas. Os resultados demonstraram princípios sem nenhuma correlação, enquanto outros com diversos objetivos relacionados, como apresentado na Figura 1.

Figura 1 - Número de relações identificadas entre Princípios e Objetivos

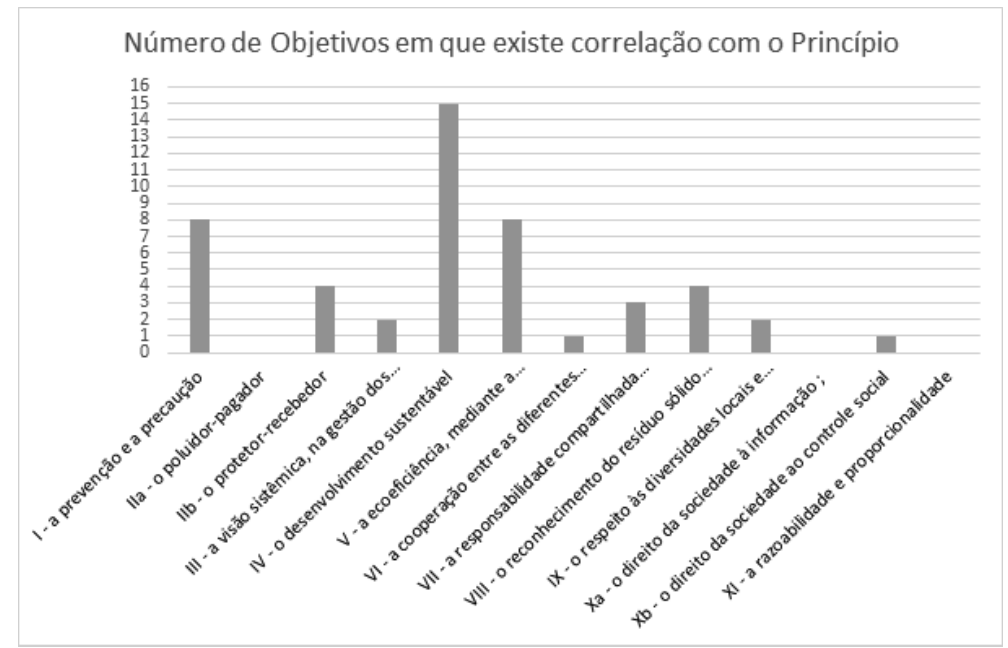

Fonte: Elaborado pelos autores.

A rede de relações estabelecida por meio da Matriz de Correlação (Quadro 1), pode ser representada por um diagrama (Figura 2) para melhor visualização. A partir desta representação, é possível observar que um princípio pode se relacionar com diversos objetivos, e um objetivo com mais de um princípio, demonstrando a diversidade, conectividade e complementaridade das relações existentes no conteúdo dos princípios e objetivos desta política. 
Ana Cristina Bagatini Marotti | Gisele Sant'Ana Fiorini Pereira | Erica Pugliesi

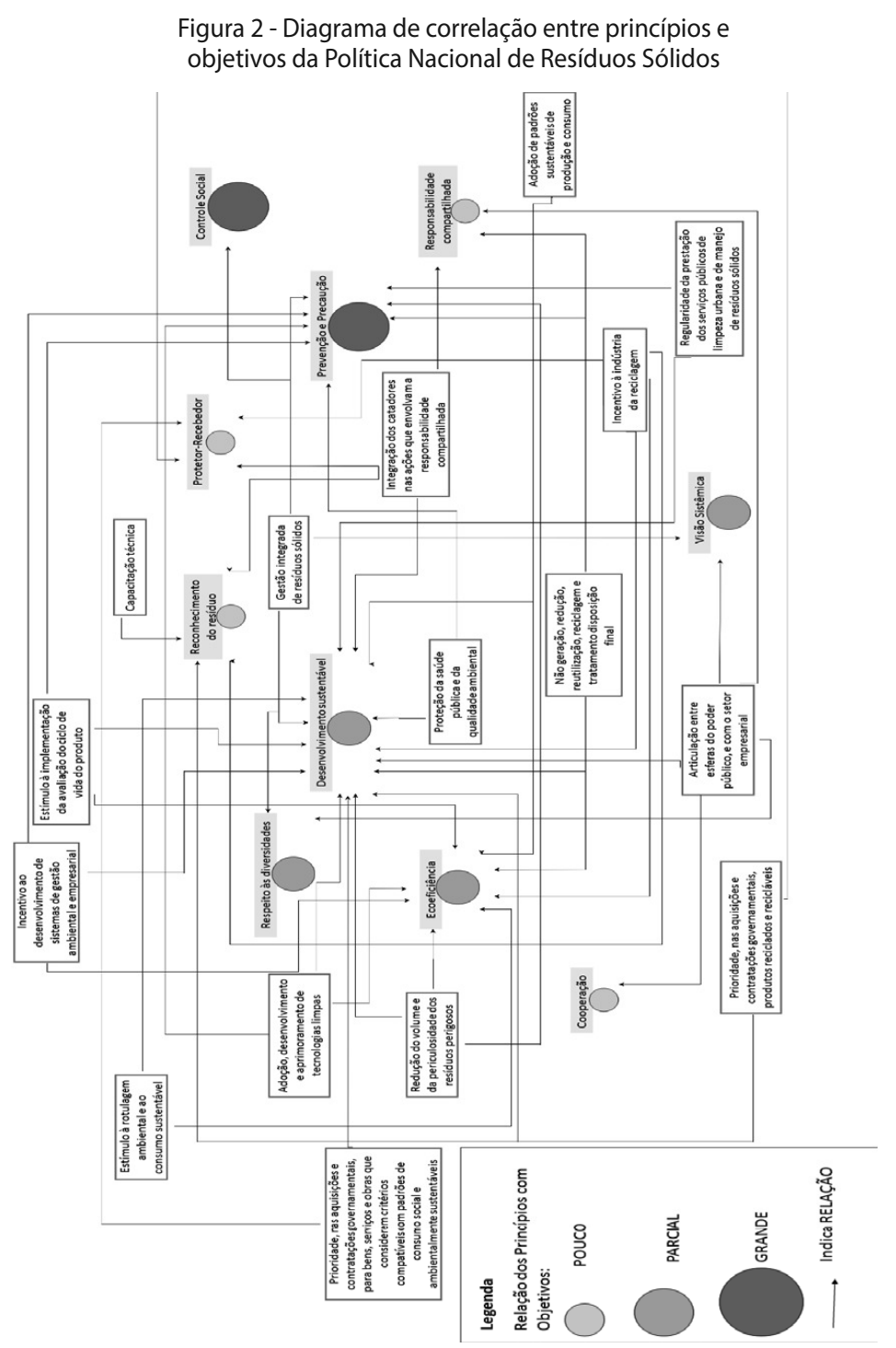

Fonte: Elaborado pelos autores. 
QUESTÕES CONTEMPORÂNEAS NA GESTÃO PÚBLICA DE RESÍDUOS SÓLIDOS: análise dos princípios da Política Nacional de Resíduos Sólidos a partir de seus objetivos e instrumentos

\section{CORRELAÇ̃̃O ENTRE PRINCÍPIOS E INSTRUMENTOS DA PNRS}

Da mesma forma que foram estabelecidas as relações existentes entre princípios e objetivos, se procedeu a análise com os princípios e instrumentos, apresentados no Quadro 2. Na matriz de correlação são indicados os princípios que se relacionam com cada instrumento, na coluna Correlação, além do atendimento de cada princípio a partir dos instrumentos relacionados, classificados a partir de uma escala.

Quadro 2 - Matriz de correlação entre princípios e instrumentos da Política Nacional de Resíduos Sólidos

\begin{tabular}{|c|c|c|c|c|}
\hline \multicolumn{3}{|c|}{ PRINCÍPIOS } & \multicolumn{2}{|l|}{ INSTRUMENTOS } \\
\hline Item & Descrição & $\begin{array}{l}\text { Atendimento } \\
\text { pelos } \\
\text { Instrumentos }\end{array}$ & Descrição & $\begin{array}{c}\text { Correlação } \\
\text { com os } \\
\text { Princípios }\end{array}$ \\
\hline A & $\begin{array}{l}\text { I - a prevenção e } \\
\text { a precaução }\end{array}$ & 4 & I - planos de resíduos sólidos & $A ; J ; L$ \\
\hline B & $\begin{array}{l}\text { Ila - o poluidor- } \\
\text { pagador }\end{array}$ & 2 & $\begin{array}{c}\| \text { - os inventários e o sistema } \\
\text { declaratório anual de resíduos sólidos }\end{array}$ & K \\
\hline C & $\begin{array}{l}\text { Illb - o protetor- } \\
\text { recebedor }\end{array}$ & 3 & $\begin{array}{l}\text { III - a coleta seletiva, os sistemas de } \\
\text { logística reversa e outras ferramentas } \\
\text { relacionadas à implementação da } \\
\text { responsabilidade compartilhada pelo } \\
\text { ciclo de vida dos produtos }\end{array}$ & $\mathrm{A} ; \mathrm{C} ; \mathrm{E} ; \mathrm{I}$ \\
\hline \multirow{2}{*}{ D } & $\begin{array}{l}\text { III - a visão } \\
\text { sistêmica, na } \\
\text { gestão dos } \\
\text { resíduos sólidos, } \\
\text { que considere }\end{array}$ & \multirow{2}{*}{2} & $\begin{array}{c}\text { IV - o incentivo à criação e ao } \\
\text { desenvolvimento de cooperativas ou } \\
\text { de outras formas de associação de } \\
\text { catadores de materiais reutilizáveis e } \\
\text { recicláveis }\end{array}$ & $\mathrm{C} ; \mathrm{E} ; \mathrm{I}$ \\
\hline & $\begin{array}{l}\text { ambiental, } \\
\text { social, cultural, } \\
\text { econômica, } \\
\text { tecnológica e de } \\
\text { saúde pública }\end{array}$ & & $\begin{array}{l}\text { V - o monitoramento e a fiscalização } \\
\text { ambiental, sanitária e agropecuária }\end{array}$ & $A ; B$ \\
\hline
\end{tabular}


Ana Cristina Bagatini Marotti | Gisele Sant'Ana Fiorini Pereira | Erica Pugliesi

\begin{tabular}{|c|c|c|c|c|}
\hline$E$ & $\begin{array}{c}\text { IV - o } \\
\text { desenvolvimento } \\
\text { sustentável }\end{array}$ & 2 & $\begin{array}{l}\mathrm{VI} \text { - a cooperação técnica e financeira } \\
\text { entre os setores público e privado para } \\
\text { o desenvolvimento de pesquisas de } \\
\text { novos produtos, métodos, processos } \\
\text { e tecnologias de gestão, reciclagem, } \\
\text { reutilização, tratamento de resíduos } \\
\text { e disposição final ambientalmente } \\
\text { adequada de rejeitos }\end{array}$ & $\mathrm{D} ; \mathrm{E} ; \mathrm{G}$ \\
\hline \multirow{7}{*}{$\mathrm{F}$} & \multirow{7}{*}{$\begin{array}{c}V \text { - a } \\
\text { ecoeficiência, } \\
\text { mediante a } \\
\text { compatibilização } \\
\text { entre o } \\
\text { fornecimento, } \\
\text { a preços } \\
\text { competitivos, de } \\
\text { bens e serviços } \\
\text { qualificados que } \\
\text { satisfaçam as } \\
\text { necessidades } \\
\text { humanas } \\
\text { e tragam } \\
\text { qualidade de } \\
\text { vida e a redução } \\
\text { do impacto } \\
\text { ambiental e } \\
\text { do consumo } \\
\text { de recursos } \\
\text { naturais a um } \\
\text { nível, no mínimo, } \\
\text { equivalente à } \\
\text { capacidade de } \\
\text { sustentação } \\
\text { estimada do } \\
\text { planeta }\end{array}$} & \multirow{7}{*}{3} & VII - a pesquisa científica e tecnológica & $E$ \\
\hline & & & VIII - a educação ambiental & $\mathrm{I} ; \mathrm{H} ; \mathrm{E}$ \\
\hline & & & $\begin{array}{l}\text { IX - os incentivos fiscais, financeiros e } \\
\text { creditícios }\end{array}$ & $C ; F$ \\
\hline & & & $\begin{array}{l}\text { X - o Fundo Nacional do Meio Ambiente } \\
\text { e o Fundo Nacional de Desenvolvimento } \\
\text { Científico e Tecnológico }\end{array}$ & $\mathrm{F}$ \\
\hline & & & $\begin{array}{c}\text { XI - o Sistema Nacional de Informações } \\
\text { sobre a Gestão dos Resíduos Sólidos } \\
\text { (Sinir) }\end{array}$ & K \\
\hline & & & $\begin{array}{l}\text { XII - o Sistema Nacional de Informações } \\
\text { em Saneamento Básico (Sinisa) }\end{array}$ & K \\
\hline & & & $\begin{array}{l}\text { XIII - os conselhos de meio ambiente e, } \\
\text { no que couber, os de saúde }\end{array}$ & $\mathrm{L}$ \\
\hline \multirow{2}{*}{ G } & $\begin{array}{l}\text { VI - a cooperação } \\
\text { entre as } \\
\text { diferentes } \\
\text { esferas do poder }\end{array}$ & \multirow{2}{*}{4} & $\begin{array}{l}\text { XIV - os órgãos colegiados municipais } \\
\text { destinados ao controle social dos } \\
\text { serviços de resíduos sólidos urbanos }\end{array}$ & $\mathrm{J} ; \mathrm{L}$ \\
\hline & $\begin{array}{l}\text { empresarial } \\
\text { e demais } \\
\text { segmentos da } \\
\text { sociedade }\end{array}$ & & $\begin{array}{c}\text { XV - o Cadastro Nacional de Operadores } \\
\text { de Resíduos Perigosos }\end{array}$ & A \\
\hline
\end{tabular}


QUESTÕES CONTEMPORÂNEAS NA GESTÃO PÚBLICA DE RESÍDUOS SÓLIDOS: análise dos princípios da Política Nacional de Resíduos Sólidos a partir de seus objetivos e instrumentos

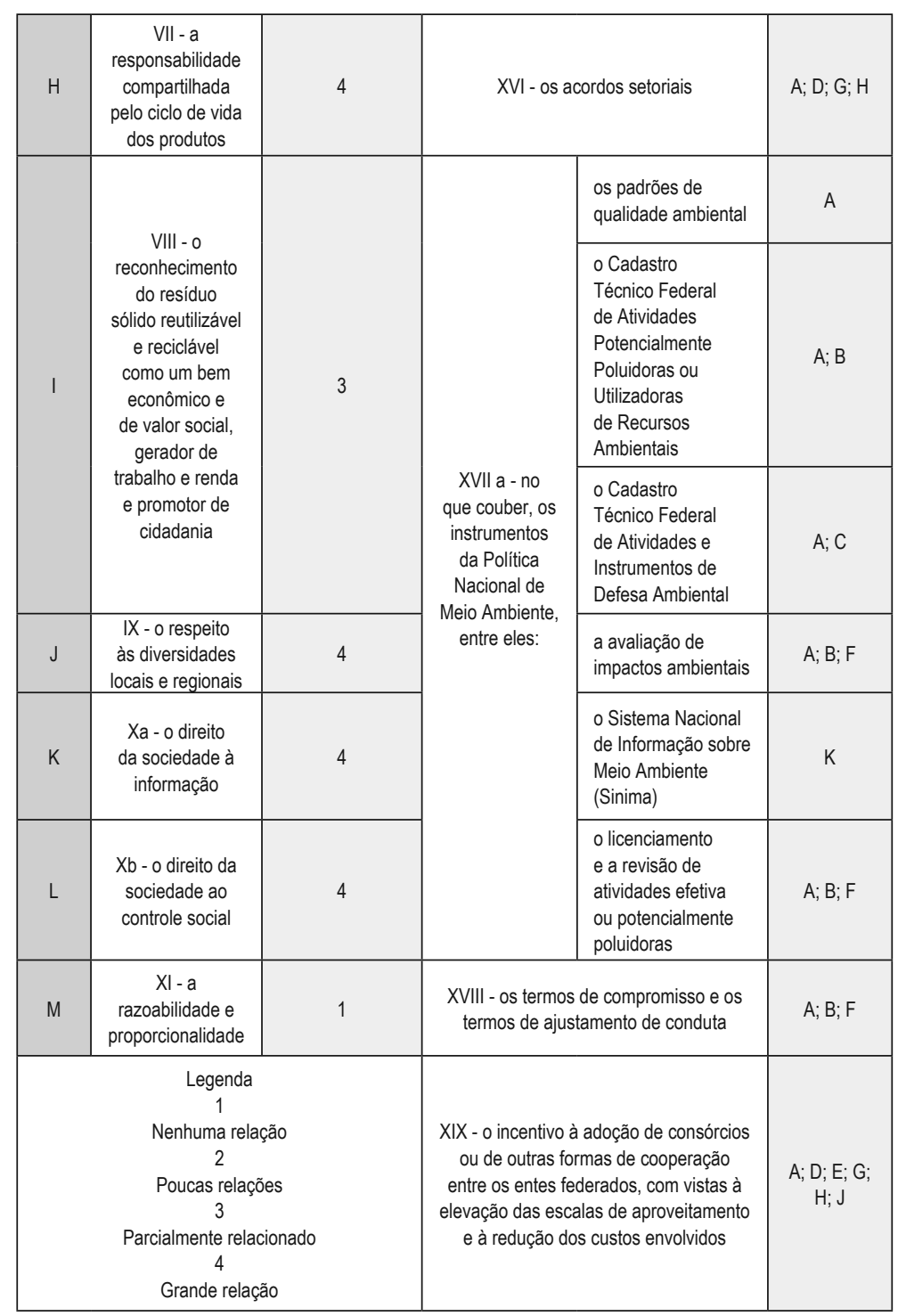

Fonte: Elaborado pelos autores.

A análise da matriz permite a identificação de um princípio não relacionado aos instrumentos da PNRS, o da razoabilidade e 
da proporcionalidade, de forma similar à análise de correlação de princípios e objetivos. Dentre os princípios identificados com poucas relações temos o do poluidor-pagador, que embora seja possível identificar alguns instrumentos relacionados, estes somente contribuem para a identificação do poluidor. Atividades relacionadas à fiscalização e penalidades estão presentes na Lei $\mathrm{n}^{\circ}$ 12.305/2010, porém não caracterizadas como instrumentos.

Apesar de os aspectos ambientais, econômicos, tecnológicos e de saúde presentes no princípio da visão sistêmica serem abordados em alguns instrumentos, este apresentou poucas relações com os instrumentos, pois os aspectos culturais e sociais da gestão de resíduos sólidos não são abordados, mesmo caracterizando-se de grande importância. O princípio do desenvolvimento sustentável pode ser associado a vários instrumentos, porém devido a sua ampla e complexa definição, ainda existem lacunas identificadas para realmente abranger as dimensões de tal princípio.

Dentre os princípios que são atendidos parcialmente pelos instrumentos estão: o princípio do protetor-recebedor que apresenta relação com instrumentos que reforçam e incentivam a coleta seletiva por meio de cooperativas ou outras formas de associação de catadores de materiais, podendo atuar como protetores do meio ambiente. Para que estas cooperativas ou associações recebam por ações de proteção, faz-se necessária a criação de instrumentos econômicos específicos. O princípio da ecoeficiência, apesar de apresentar alguns instrumentos relacionados, não se relaciona a instrumentos de garantia do fornecimento de bens e serviços ambientalmente adequados e de qualidade. O princípio do reconhecimento do resíduo sólido reutilizável e reciclável foi considerado parcialmente atendido por se relacionar com os instrumentos de incentivo às cooperativas e associações de catadores de materiais, porém não são reconhecidas outras formas de trabalho e de fontes de renda para além da coleta seletiva.

O princípio da responsabilidade compartilhada apresenta grande relação com os objetivos para seu atendimento por estar relacionado aos instrumentos de educação ambiental, aos acordos setoriais e aos incentivos a consórcios, podendo compreender uma grande diversidade de agentes e ações. O princípio da cooperação pode ser relacionado aos instrumentos de cooperação técnica e financeira entre os setores público e privado, de acordo setoriais e de 
QUESTÕES CONTEMPORÂNEAS NA GESTÃO PÚBLICA DE RESÍDUOS SÓLIDOS: análise dos princípios da Política Nacional de Resíduos Sólidos a partir de seus objetivos e instrumentos

incentivo à adoção de consórcios ou outras formas de cooperação, visando à cooperação de esferas do governo e do setor privado. Outros princípios atendidos pelos instrumentos da PNRS são: princípios da prevenção e da precaução, do respeito às diversidades locais e regionais, do direito da sociedade à informação e do direito da sociedade ao controle social.

De forma análoga aos resultados da análise anterior, as relações existentes entre os princípios e instrumentos foram variadas, ocorrendo princípios sem instrumentos relacionados e outros com diversos princípios relacionados, representados na Figura 3.

Figura 3 - Número de relações identificadas entre Princípios e Instrumentos

Número de Instrumentos em que existe correlação com o Princípio
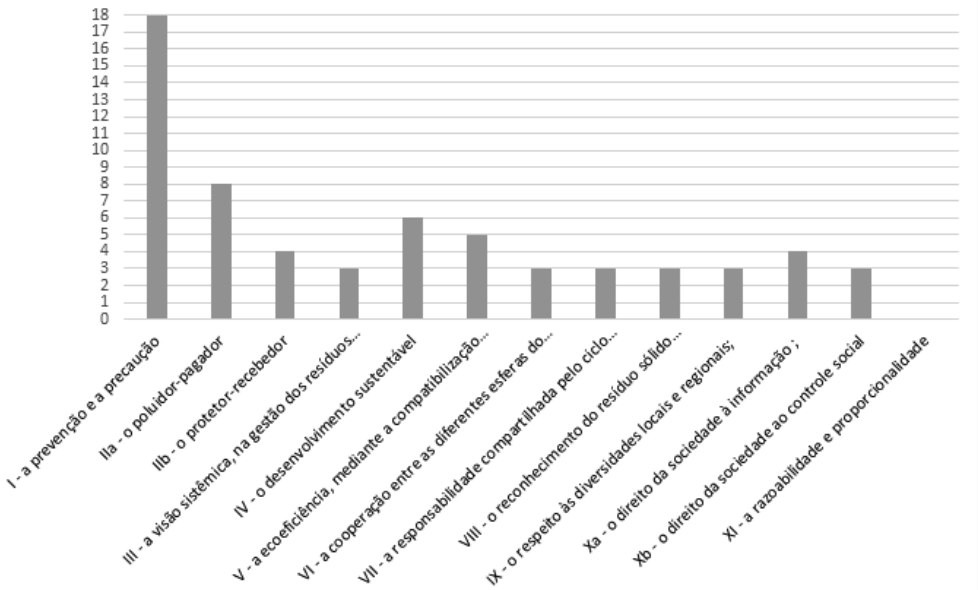

Fonte: Elaborado pelos autores.

A Figura 4 representa em um diagrama a rede de relações estabelecida por meio da Matriz de Correlação (Quadro 2), permitindo uma melhor visualização. É possível observar que um princípio pode se correlacionar com um ou mais instrumentos, e um instrumento pode estar relacionado a mais de um princípio, denotando a complexidade das ações decorrentes da aplicação da PNRS. 
Figura 4 - Diagrama de correlação entre princípios e instrumentos da Política Nacional de Resíduos Sólidos

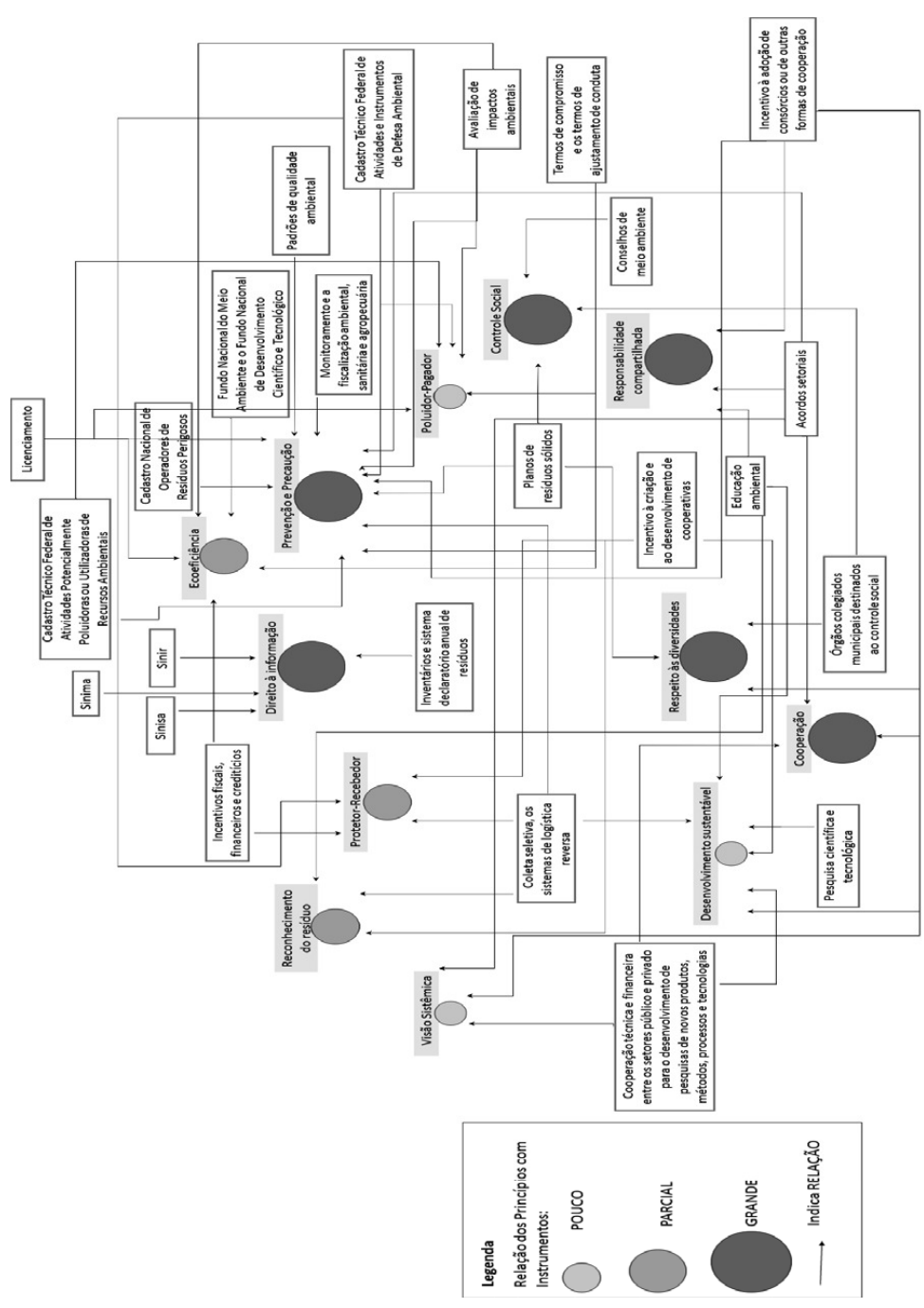

Fonte: Elaborado pelos autores. 


\section{CONCLUSÃO}

A PNRS é o principal instrumento normativo para a gestão e gerenciamento dos resíduos sólidos no Brasil, enfatizando-se a importância da estrutura apresentada na Lei de suas disposições e conteúdo, dentre eles seus princípios, objetivos e instrumentos. A harmonia e relação entre estes elementos são fundamentais para a coesão da lei enquanto normativa, proporcionando melhor compreensão e a efetividade da mesma. Os princípios são o eixo central da lei, carreando suas fundamentações mais importantes, que fomentam os objetivos e as formas de alcançá-los, ou seja, os instrumentos. A análise das relações existentes entre estes elementos permitiu a identificação da complementaridade dos mesmos, além da identificação de outros elementos que independem destas relações para a efetivação da política, pois são fundamentados como direitos constitucionais.

As correlações estabelecidas entre os princípios, objetivos e instrumentos não obedecem a uma lógica direta ou de correspondência total, sendo que os princípios podem apresentar um ou mais objetivos ou instrumentos para sua aplicação; e, objetivos e instrumentos podem responder a mais de um princípio. Do mesmo modo, a quantidade de relações estabelecidas entre estes elementos não garantem a aplicação plena do princípio. A exemplo, os princípios da prevenção e da precaução e o princípio do direito da sociedade ao controle social apresentaram um maior atendimento tanto pelos objetivos quanto pelos instrumentos. Tal fato demonstra que a PNRS apresenta - além de diversos mecanismos para evitar possíveis ocorrências de danos ambientais e à saúde pública - mecanismos que possibilitam a participação da sociedade na aplicação da política pública para o gerenciamento e a gestão dos resíduos sólidos. Por outro lado, o princípio do direito da sociedade à informação, que não apresenta relações diretas com os objetivos da lei, é majoritariamente atendido pelos instrumentos propostos.

Dessa forma considera-se que a PNRS apresenta princípios correlacionados e atendidos pelos objetivos e instrumentos de forma distinta, a depender da complexidade e fundamentação do princípio analisado. Além da coesão de relações entre princípios, objetivos e instrumentos da Lei, os demais elementos como as diretrizes e disposições que a formam, fundamentam seu contexto de aplicação. 
Por fim, redobra-se de importância esta normativa como marco legislativo na gestão e gerenciamento dos resíduos sólidos no país, a qual incorpora aspectos fundamentais e inovadores alinhados às demais políticas ambientais brasileiras. A compreensão da integralidade de seu conteúdo é fator fundamental para sua aplicação e condicionante para a efetividade enquanto política pública.

\section{REFERENCIAS}

ARAÚJO, S. M. V. G. de. O desafio da aplicação da lei dos resíduos sólidos. Brasília, DF: Câmara dos Deputados, set. 2013.

BRASIL. Constituição (1988). Constituição da República Federativa do Brasil. Brasília, DF, 1988.

Presidência da República. Lei no 11.445 de 05 de janeiro de 2007. Política Federal de Saneamento Básico. Estabelece diretrizes nacionais para o saneamento básico; altera as Leis nos 6.766, de 19 de dezembro de 1979, 8.036, de 11 de maio de 1990, 8.666, de 21 de junho de 1993, 8.987, de 13 de fevereiro de 1995; revoga a Lei no 6.528 , de 11 de maio de 1978; e dá outras providências. Diário Oficial da União, Brasília, DF, 2007. Disponível em: $<$ http://www.planalto. gov.br/ccivil_03/_ato2007-2010/2007/lei/111445.htm>. Acesso em: 1 nov. 2016.

Lei ${ }^{\circ} 12.305$, de 2 de agosto de 2010. Política Nacional de Resíduos Sólidos. Institui a Política Nacional de Resíduos Sólidos; altera a Lei no 9.605, de 12 de fevereiro de 1998; e dá outras providências. Diário Oficial da União, Brasília, DF, 2010. Disponível em: $<$ http://www.planalto.gov.br/ccivil_03/_ato2007-2010/2010/lei/ 112305.htm>. Acesso em: 1 nov. 2016.

Lei $n^{\circ} 6.938$ de 31 de agosto de 1981. Política Nacional do Meio Ambiente. Dispõe sobre a Política Nacional do Meio Ambiente, seus fins e mecanismos de formulação e aplicação, e dá outras providências. Diário Oficial da União, Brasília, DF, 1981. Disponível em:<http://www.planalto.gov.br/ccivil_03/leis/L6938. $\mathrm{htm}>$. Acesso em: 1 nov. 2016.

BUARQUE, S. C. Metodologia de planejamento do desenvolvimento local e municipal sustentável: projeto de cooperação técnica INCRA/ IICA. Brasília, DF, 1999.

FARIA, C. R. S. M. A Política Nacional de Resíduos Sólidos. Boletim do Legislativo, Brasília, DF, n. 15. Jun. 2012. 
QUESTÕES CONTEMPORÂNEAS NA GESTÃO PÚBLICA DE RESÍDUOS SÓLIDOS: análise dos princípios da Política Nacional de Resíduos Sólidos a partir de seus objetivos e instrumentos

GALUPPO, M. C. Os princípios jurídicos no Estado Democrático de Direito: ensaio sobre o modo de sua aplicação. Revista de Informação Legislativa, Brasília, DF, ano 36, n. 143, p. 191-210, jul./set., 1999.

GODOY, M. B. R. B. Dificuldades para aplicar a Lei da Política Nacional de Resíduos Sólidos no Brasil. Caderno de Geografia, Belo Horizonte, v. 23, n. 39, p. 1-12, 2013.

GOUVEIA, N. Resíduos sólidos urbanos: impactos socioambientais e perspectiva de manejo sustentável com inclusão social. Revista Ciências e Saúde Coletiva, Rio de Janeiro, v. 17, n. 6, p. 1503-1510, jun. 2012.

JURAS, I. A. G. M. Legislação sobre Resíduos Sólidos: comparação da Lei 12.305/2010 com a legislação de países desenvolvidos. Brasília, DF: Câmara dos Deputados, abr. 2012.

MACHADO, P. A. L. Princípios da Política Nacional de Resíduos Sólidos. In: JARDIM, A.; YOSHIDA, C.; MACHADO FILHO, J. V. (Orgs.). Política Nacional, gestão e gerenciamento de resíduos sólidos. Barueri: Manole, 2012.

NASCIMENTO NETO, P. N.; MOREIRA, T. A. Política Nacional de Resíduos Sólidos: reflexões acerca do novo marco regulatório nacional. Revista Brasileira de Ciências Ambientais, São Paulo, v. 15, p. 10-19, 2010.

ORGANIZAÇÃO DAS NAÇÕES UNIDAS. A ONU e o meio ambiente. [S. 1.], [2016]. Disponível em: $<$ https://nacoesunidas.org/ acao/meio-ambiente/>. Acesso em: 23 nov. 2016.

PIRES, D. B. de S. Princípio da proporcionalidade versus razoabilidade. Âmbito Jurídico, Rio Grande, ano 10, n. 46, out 2007. Disponível em: $<$ http://www.ambito-juridico.com.br/site/index. php?n_link=revista_artigos_leitura\&artigo_id=2428>. Acesso em: 1 jan. 2017.

RAUBER, M. E. Apontamentos sobre a Política Nacional de Resíduos Sólidos, instituída pela Lei Federal n ${ }^{\circ} 12.305$ de 02.08.2010. Revista Eletrônica em Gestão, Educação e Tecnologia Ambiental, Santa Maria, RS, v. 4, n. 4, p. 1-24, 2011.

SOUZA, C. Políticas Públicas: uma revisão da literatura. Sociologias, Porto Alegre, ano 8, n. 16, p. 20-45, jul./dez. 2006.

VERDAN, T. L. O Princípio da Cooperação na Lei da Política Nacional de Resíduos Sólidos: Breves Comentários. Conteúdo 
Jurídico, Brasília, DF, out. 2013. Disponível em:<http://www.

conteudojuridico.com.br/pdf/cj045385.pdf $>$. Acesso em: 23 nov. 2016.

YOSHIDA, C. Competência e as diretrizes da PNRS: conflitos e

critérios de harmonização entre as demais legislações e normas. In:

JARDIM, A.; YOSHIDA, C.; MACHADO FILHO, J. V. (Orgs.).

Política Nacional, gestão e gerenciamento de resíduos sólidos.

Barueri: Manole, 2012. 